\begin{tabular}{|c|c|}
\hline $\begin{array}{l}\text { Chemistry of } \\
\text { Metals and Allove }\end{array}$ & 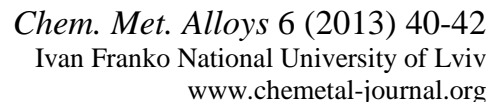 \\
\hline
\end{tabular}

\title{
Electrochemical synthesis of lithium fullerides
}

\author{
A.O. ZUL'FIGAROV ${ }^{1}$, V.A. POTASKALOV ${ }^{1}$, A.P. POMYTKIN ${ }^{1}$, A.A. ANDRIIKO ${ }^{1}$, D.V. SHCHUR ${ }^{2}$, \\ O.A. KRIUKOVA ${ }^{3}$, V.G. KHOMENKO ${ }^{3}$ \\ ${ }^{1}$ Chair of General and Inorganic Chemistry, National Technical University of Ukraine \\ “Kyiv Polytechnic Institute”, 37 Prospekt Peremogy, Kyiv, Ukraine \\ ${ }^{2}$ Institute of Material Science Problems, National Academy of Sciences of Ukraine, \\ 3 Krzhyzhanovskogo St., Kyiv, Ukraine \\ ${ }^{3}$ National University of Technologies and Design, 2 Nemyrovycha-Danchenka St., Kyiv, Ukraine \\ * Corresponding author. E-mail: andriiko_aa@ukr.net
}

Received June 3, 2013; accepted June 19, 2013; available on-line November 4, 2013

The electrochemical reaction of $\mathrm{Li}$ with fullerene in an aprotic electrolyte was studied. It was found that a lithium-rich fulleride with approximate formula $\mathrm{Li}_{10} \mathrm{C}_{60}$ can be obtained in the presence of a catalyst. This amount of $\mathrm{Li}$ is irreversibly incorporated into the structure. Additionally, 4-5 atoms can be introduced reversibly, thus allowing cycling the material with an initial reversible capacity of about $180 \mathrm{mAh} \cdot \mathrm{g}^{-1}$. The pyrolysis product of a heterometal complex with monoaminoethanol ligands is shown to be a good catalyst for this process.

Fullerene / Lithium fulleride / Electrochemical synthesis

\section{Introduction}

Since the discovery of carbon allotrope fullerenes in 1985 [1], a large number of researches have been devoted to the chemistry of these substances. Many organic and inorganic derivatives have been obtained and their properties studied [2].

Among the inorganic compounds of fullerenes, the fullerides of alkali and alkali earth metals are of significant interest [3]. The alkali metal compounds of the fullerene $\mathrm{C}_{60}$ with composition $M e_{3} \mathrm{C}_{60}$ are the most studied ones because of their superconductivity below 30-50 K [4].

It is known that the outer surface of the spherical molecule $\mathrm{C}_{60}$ contains 12 pentagons and 20 hexagons [5]. Since a common graphene plane of graphite can accommodate up to 1 alkali metal atom per 1 of its 3 hexagons $\mathrm{C}_{6}$ (which corresponds to the graphite intercalation compound $\mathrm{MeC}_{6}$ [6]), one can expect the formation of metal-rich compounds of fullerene $\mathrm{C}_{60}$ with approximate composition $\mathrm{Me}_{6} \mathrm{C}_{60}$. Effectively, $M e_{6} \mathrm{C}_{60}$ compounds with $b c c$ lattice have been obtained [7]. However, it was found that such metalreach fullerides can be formed only with smaller (Li) atoms. Moreover, in the case of $\mathrm{Li}$, further doping is possible, resulting in the formation of a product of composition $\mathrm{Li}_{15} \mathrm{C}_{60}$ with $f c c$ packing of the fullerene ions [8]. The aim of this paper was to study the possibility of preparation of such Li-rich fullerides by the electrochemical method.
The cathodic reduction of $\mathrm{Li}^{+}$ions on a fullerenebased electrode under controlled current was chosen for this purpose. In some of the experiments, the electrode contained additives of a trinuclear complex compound of $2 \mathrm{Co}-\mathrm{Ni}$ with aminoalcohol ligands, which, as shown earlier, possess electrocatalytic properties with regards to the reaction of $\mathrm{Li}$ intercalation into graphite $[9,10]$.

\section{Experimental}

The fullerenes were obtained by the plasma arc method, which allows producing a large variety of carbon nanomaterials, as described in $[11,12]$. The sample selected for further investigations contained 85 wt.\% of $\mathrm{C}_{60}, 14$ wt.\% of $\mathrm{C}_{70}$, and about $1 \mathrm{wt} . \%$ of higher fullerenes.

The electrochemical reaction of $\mathrm{Li}$ with the fullerene was performed in a coin cell with a Li metal anode, $1 \mathrm{M}$ solution of $\mathrm{LiPF}_{6}$ in an equimolar mixture of ethylene carbonate and methyl carbonate as the electrolyte, and a fullerene-based electrode as the cathode. The cathode mass contained $85 \mathrm{wt} . \%$ of the fullerene, $10 \mathrm{wt} . \%$ of carbon black (ABG-10) as the conductive additive and $5 \mathrm{wt} \%$ of polyvinylidene fluoride (PVDF) as the binder. The experiments were carried out under galvanostatic conditions using a PC-governed power source with an operating current of $40-50 \mathrm{~mA} \cdot \mathrm{g}^{-1}$. 
The catalyst, a heterometal $2 \mathrm{Co}-\mathrm{Ni}$ compound with monoaminoethanol, was synthesized in two steps. First, an inner complex of $\mathrm{Co}$ (III) with aminoalcohol was obtained by means of the reaction of $\mathrm{Co}$ (II) nitrate with an aminoalcohol ligand in alkali ethanol medium in the presence of atmospheric oxygen according to the equation:

$$
\begin{array}{r}
4 \mathrm{Co}\left(\mathrm{NO}_{3}\right)_{2}+12 \mathrm{Hetm}+8 \mathrm{KOH}+\mathrm{O}_{2}= \\
4 \mathrm{Co}(\text { Etm })_{3}+8 \mathrm{KNO}_{3}+10 \mathrm{H}_{2} \mathrm{O}
\end{array}
$$

where Hetm $=\mathrm{H}_{2} \mathrm{NCH}_{2} \mathrm{CH}_{2} \mathrm{OH}$ (the notation Etm means the deprotonated form of Hetm, monoaminoethanol).

More details of the synthesis procedure can be found in [13-15]. Then polynuclear complexes were synthesized by reacting this complex with a solution of potassium nitrate in isopropanol for 3 days.

The chemical reaction of the formation of the trinuclear complexes can be written as follows:

$$
\begin{array}{r}
\mathrm{Ni}\left(\mathrm{NO}_{3}\right)_{2}+2 \mathrm{fac}-\left[\mathrm{Co}(\mathrm{Etm})_{3}\right] \rightarrow \\
{\left[\mathrm{Ni}(\mathrm{CoEtm})_{2}\right]\left(\mathrm{NO}_{3}\right)_{2}}
\end{array}
$$

Grafting of the complexes onto the surface of fullerene was performed by means of adsorption from an isopropanol solution. The time of treatment was 2 days, the content of complex in the solution was established to be 0.05 mole per $1 \mathrm{~g}$ of the sample. About $4.5 \mathrm{wt} . \%$ of the metals $(2 \mathrm{Co}+\mathrm{Ni})$ were adsorbed under these conditions. After that, the samples were filtered and the product dried at room temperature.

Some samples were pyrolyzed in an atmosphere of pure argon for $1 \mathrm{~h}$. The optimal temperature for the pyrolysis was established to be $500^{\circ} \mathrm{C}$ [10].

IR-spectra of the samples were taken on a Specord 75IR spectrometer in the range $400-4000 \mathrm{~cm}^{-1}$, using tablets of $\mathrm{KBr}$.

\section{Results and discussion}

Fig. 1 presents galvanostatic curves of the reduction of $\mathrm{Li}^{+}$ions on fullerenes in terms of the operating voltage $v s$. the number of $\mathrm{Li}$ atoms per 1 molecule of $\mathrm{C}_{60}$.

As follows from the experimental data, less than $1 \mathrm{Li}$ atom can be introduced into the structure of the fulleride if no catalyst is used (curve 1 of Fig. 1). Applying the $2 \mathrm{Co}-\mathrm{Ni}$ complex compound as it is, that is, without subsequent thermal treatment (curve 2 of Fig. 2) made it possible to introduce about $4 \mathrm{Li}$ atoms per $\mathrm{C}_{60}$ molecule. The electrochemical reaction is irreversible in both cases (that is, the $\mathrm{Li}$ atoms cannot be extracted by applying a reverse anodic current).

The reduction pattern differs significantly for the sample with the complex pyrolyzed at $500^{\circ} \mathrm{C}$ in argon atmosphere (curve 3 of Fig. 1). One can observe three distinct reduction steps: a - formation of $\mathrm{Li}_{4} \mathrm{C}_{60}$ at $\sim 1 \mathrm{~V} v s . \mathrm{Li} ; \mathrm{b}-\mathrm{Li}_{10} \mathrm{C}_{60}$ is formed at $0.75 \mathrm{~V} v s$. $\mathrm{Li}$ and $\mathrm{c}$ - finally, the structure accommodates additional Li up to approximately 16 atoms per $\mathrm{C}_{60}$. This is in good agreement with the compositions obtained by a chemical method [8].

Fig. 2 shows IR-spectra of the initial sample (curve 1) and fullerene modified by the pyrolysis products of the heterometal complex compound (curve 2).

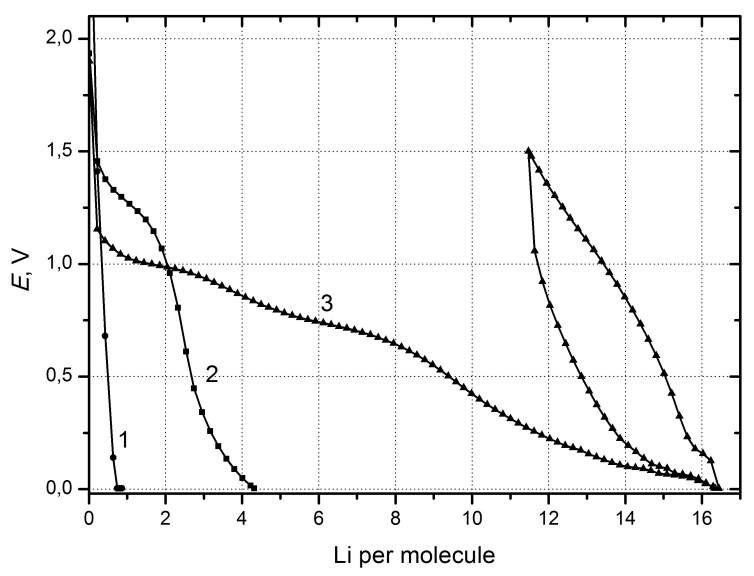

Fig. 1 Galvanostatic curves of $\mathrm{Li}^{+}$reduction on fullerene $\mathrm{C}_{60}$ at a specific current of $40 \mathrm{~mA} \cdot \mathrm{g}^{-1}$. 1 -initial sample; 2 -fullerene with grafted 2Co-Ni complex with monoethanol amine; 3 -the same with the complex pyrolized in argon at $500^{\circ} \mathrm{C}$.

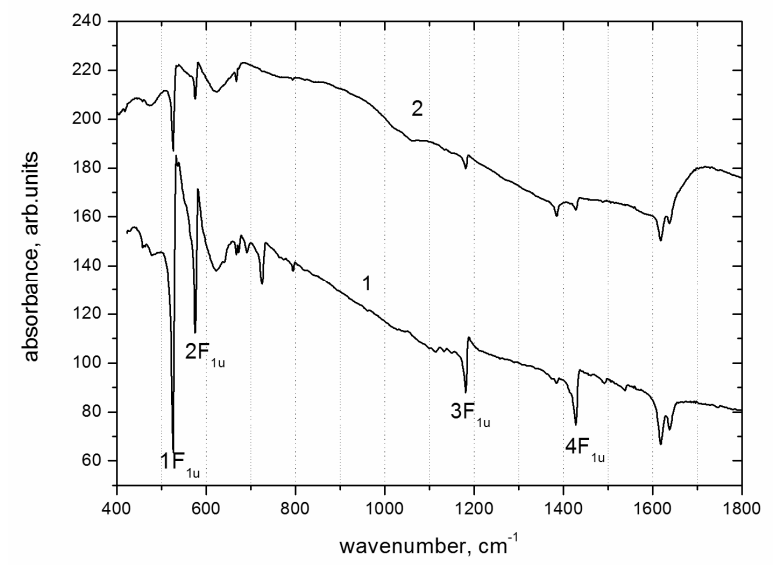

Fig. 2 IR-spectra of initial fullerene (1) and of the sample modified by $\left[\mathrm{Ni}(\mathrm{CoEtm})_{2}\right]\left(\mathrm{NO}_{3}\right)_{2}$ complex pyrolized in $\mathrm{Ar}$ at $500^{\circ} \mathrm{C}$ (2). Four vibration bands of $\mathrm{C}_{60}$ are marked.

As follows from the spectra, the wavenumbers of four vibration modes of $\mathrm{C}_{60}, \quad 1 \mathrm{~F}_{1 \mathrm{u}}\left(526 \mathrm{~cm}^{-1}\right)$, $2 \mathrm{~F}_{1 \mathrm{u}} \quad\left(576 \mathrm{~cm}^{-1}\right), \quad 3 \mathrm{~F}_{1 \mathrm{u}} \quad\left(1182 \mathrm{~cm}^{-1}\right), \quad$ and $4 \mathrm{~F}_{1 \mathrm{u}}$ $\left(1428 \mathrm{~cm}^{-1}\right)$, are in good agreement with data reported in the literature [16]. The positions of these bands do not change after the modification, and no additional bands appear. On the contrary, the three bands at $692 \mathrm{~cm}^{-1}, 725 \mathrm{~cm}^{-1}$ and $795 \mathrm{~cm}^{-1}$ vanish. This may indicate the removal of oxygen-containing admixtures from the sample in the course of annealing the sample with grafted complex in inert atmosphere. 
Thus, it seems that the modification of the fullerene does not affect the structure of the sample, and the catalytic effect consists in facilitating the charge transfer during the reduction process, as in the case of intercalation of Li into graphite $[9,10]$.

As follows from the electrochemical experiments, the process of insertion of up to about 10 atoms of $\mathrm{Li}$ per molecule is irreversible, that is, it cannot be extracted upon application of a reverse anodic current. This fact is in agreement with the irreversible electrochemical behaviour of the lithium fulleride mesoporous tantalum oxide reported in [17].

It is worthwhile noting that the structure of the $\mathrm{Li}$ fulleride with approximate composition $\mathrm{Li}_{10} \mathrm{C}_{60}$ is able to reversibly take up some additional amount of $\mathrm{Li}$, about 4-5 atoms per formula. It can be repeatedly extracted from the sample in a reverse anode process (see the loop in curve 3, Fig. 1). It gives a reversible specific capacity of about $180 \mathrm{mAh} \cdot \mathrm{g}^{-1}$. This capacity fades in the course of repeated cycling, as shown in Fig. 3. Thus, this result, being interesting from the scientific point of view, is so far not of practical importance for Li battery technology.

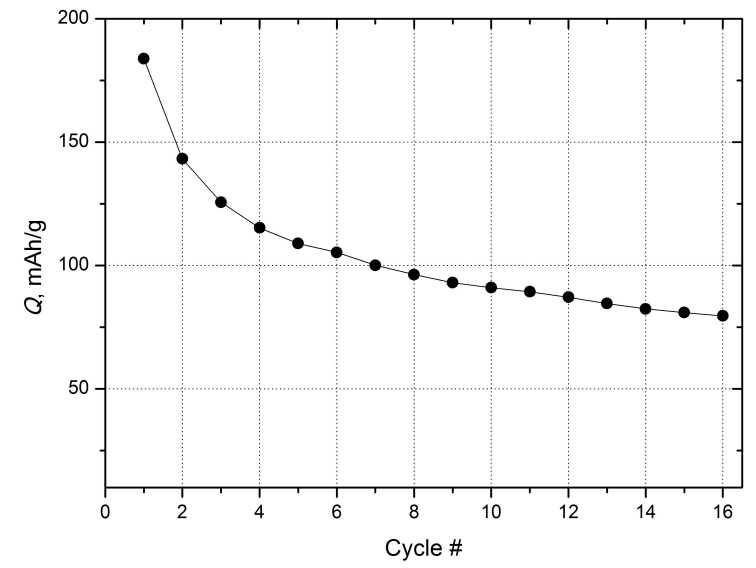

Fig. 3 Reversible capacity of lithium fulleride in the course of cycling.

\section{Conclusions}

A fulleride with high content of lithium (about $\mathrm{Li}_{10} \mathrm{C}_{60}$ ) could be obtained by electrochemical reduction of $\mathrm{Li}^{+}$ions on a fullerene-based electrode in the presence of the pyrolysis products of a $\left[\mathrm{Ni}(\mathrm{CoEtm})_{2}\right)_{2}\left(\mathrm{NO}_{3}\right)_{2}$ complex as catalyst. The reaction proceeds irreversibly.

The compound is able to incorporate an additional amount of $\mathrm{Li}$ up to the composition $\mathrm{Li}_{16} \mathrm{C}_{60}$. This part of the reaction is electrochemically reversible - about 5-6 atoms of Li per formula can be extracted by means of anode current.

\section{References}

[1] H.W. Kroto, J.R. Heath, S.C. O'Brien, R.F. Curl, R.E. Smalley, Nature 318 (1985) 162-163.

[2] T. Akasaka, F. Wudl, S. Nagase, Chemistry of Nanocarbons, John Wiley \& Sons, 2010, 526 p.

[3] D.W. Murphy, M.J. Rosseinsky, R.M. Fleming, R. Tycko, A.P. Ramirez, R.C. Haddon, T. Siegrist, G. Dabbagh, J.C. Tully, R.E. Walstedt, J. Phys. Chem. Solids 53 (1992) 1321-1332.

[4] Y. Iwasa, T. Takenobu, J. Phys.: Condens. Matter 15 (2003) R495.

[5] A.R. Kortan, N. Kopylov, S.N. Glarum, E.M. Gyorgy, A.P. Ramirez, R.M. Fleming, F.A. Tiel, R.C. Haddon, Nature 355 (1992) 529.

[6] R. Juza, V. Wehle, Nature 52 (1965) 560.

[7] O. Zhou, J.E. Fisher, N. Coustel, S. Kysia, Q. Zhu, A.R. McGie, W.J. Romanov, J.P.M. Junoir, A.B. Smith, D.E. Cox, Nature 351 (1991) 452.

[8] T. Shiroka, M. Ricco, F. Barbieri, E. Zannoni, M. Tomaselli, Phys. Solid State 44 (2002) 521.

[9] L.G. Reiter, V.A. Potaskalov, A.A. Andriiko, V.S. Kublanovsky, Yu.K. Pirskiy, M.A. Chmilenko, V.I. Lisin, S.M. Chmilenko, In: I. Barsukov (Ed.), New Carbon-based Materials for Electrochemical Energy Storage Systems, Springer, 2006, pp. 333-344.

[10] A.A. Andriiko, V.A. Potaskalov, A.O. Zul'figarov, O.A.Krukova, Sci. Bull. Chernivtsi State Univ. 399-400 (2008) 80-82 (in Ukrainian).

[11] A.D. Zolotarenko, D.V. Shchur, A.F. Savenko, V.M. Avdeev, S.N. Kaverina, S.A. Firstov, S.Yu. Zaginaichenko, V.V. Skorokhod, Nanosist., Nanomater., Nanotekhnol. 3 (2005) 197-203.

[12] A.D. Zolotarenko, V.M. Avdeev, S.A. Firstov, D.V. Shchur, S.Yu Zaginaichenko,, E.I. Golovko, Nanosist., Nanomater., Nanotekhnol. 3 (2005) 1133-1144.

[13] V.V. Udovenko, A.N. Gerasenkova, Zh. Neorg. Khim. 13 (1968) 3012-3013.

[14] O.N. Stepanenko, V.A. Potaskalov, N.I. Potaskalova, Ukr. Khim. Zh. 69 (2003) 78-80.

[15] O.N. Stepanenko, V.A. Potaskalov, V.V. Trachevskii, Ukr. Khim. Zh. 67 (2001) 70-74.

[16] B. Chase, N. Herron, E. Holler, J. Phys. Chem. 96 (1992) 4262-4266.

[17] B.O. Skadtchenko, M. Trudeau, Kwon Chai-Won, B. Dunn, D. Antonelli, Chem. Mater. 16(15) (2004) 2886-2894.

Proceeding of the XIV Scientific Conference "Lviv Chemical Readings - 2013",

Lviv, May 26-29, 2013. 